\title{
LEARNERS' EXPERIENCES IN INTEGRATING DIGITAL TECHNOLOGY \\ IN THEIR FOREIGN LANGUAGE LEARNING
}

\section{FATYANA RACHMA SAPUTRI}

Indonesia University of Education, Indonesia

\begin{abstract}
The high technological developments make foreign language contacts easier than ever. Learners not only get those language contacts in the classroom, but also outside of the class. With the exposures from kinds of digital technology, learners get more varied and unique contacts. From this case, the different exposures of target languages might influences learners' competencies in learning the language. Identifying learners' experiences in integrating digital technology for their foreign language learning was the objective of this research. In other words, this research was aimed to answer this research question: how do learners experience digital technology for their foreign language learning? This research is in the form of qualitative which includes three learners as participants. Based on learners' experiences, digital technology gives more benefits for autodidact learning than in a formal education. The result of this study also showed that the impact of technology is more pronounced to the development of receptive skills. Meanwhile, instead of learning languages in a classroom, learners in this $21^{\text {st }}$ century have more access to gain information they want to improve language skills.
\end{abstract}

KEYWORDS: Digital Technology, Ict, Foreign Language \& Learners' Experiences

Received: Mar 23, 2018; Accepted: Apr 13, 2018; Published: Apr 30, 2018; Paper Id.: IJELJUN20186

\section{INTRODUCTION}

The world rapidly changes and influences ones' environment in absorbing languages around them. One of the issues that are rapidly growing is the role of technology in providing different inputs and learning processes. Technology becomes a culture which is embodied in today's society, affecting many aspects of life, including the area of education works. In foreign language learning, the technology could be functioned as one of the learning media. The high technological developments make language contacts easier than ever. Learners can easily access target languages through digital books, television programs, radio, videos, international journals, movies, and so on. In other words, the exposure of target languages can be done with different sources.

The exposures from kinds of digital technology give learners chances to get more varied and unique contacts than previous generations. In the past, no matter how different the learners were, teachers often treated them in the same ways (Schleicher, 2012). However, in this $21^{\text {st }}$ century, learners have more access to develop their own languages. They have rights to choose their learning styles, strategies, materials, and what languages they want to learn. It indicates that learners do not only get language learning in classrooms, but also outside of the class with the use of digital technology. With digital technology, it is easier for learners to get information. On the other hand, since there are many sources and available materials, learners are required to have skills in filtering the input so that they could process the information. 
From the issue, investigating how digital technology works for foreign language learning and how learners integrate digital technology could give benefits to explore more about technological usages in the education field. In other words, this research was aimed to answer this research question: how do learners experience digital technology for their foreign language learning?

This research focused on identifying learners' experiences in integrating digital technology for their foreign language learning. It covers their daily use, available materials, strengths, weaknesses, challenges, and the impacts for their learning. Some possible ways of giving significances might be presented by this research. For other learners, they would get new information and perspectives in using digital technology for foreign language learning. For teachers, it gives benefits for them in designing activities. They might have more ideas of what facilities provided by technology for learners' language learning.

\section{TECHNOLOGY AND LEARNERS' GENERATION}

Each generation encounters different situations where technology emerged in their era. The early generation is Builders who were born before 1945. Then, Baby Boomers are people who were born between 1945 until 1965. Since they face different kinds of technology developments, they could be classified as digital immigrants. After that, there are X, Y, $\mathrm{Z}$, and Millennial generations. The current generation is Alfa.

The younger generations are commonly considered as digital natives where they interact with various technologies frequently along with their growth. They implement technology as daily life tools which complete everyday activities. However, not all young learners who were born in the digital age could be categorized as digital native due to their skills which might not match to the concept of implications. For an example, they may not transfer their knowledge and skills of social media to support language learning (Lintunen, 2017).

\section{USING DIGITAL TECHNOLOGY IN LEARNING ACTIVITIES}

Technology is also integrated into learning activities. A variety of conveniences are offered to help the learning process. However, increasing the availability of technological resources does not imply replacing the traditional teaching models significantly (Area in Villafuerte and Romero, 2017). Although technology is a part of the globalization process which affects education works and cultures (Graddol in Pun, 2013), it could not replace teachers and face-to-face classrooms (Sharma and Barrett, 2007). Instead of replacing the teachers, technology is something that can be used to enhance language learning. Rather than modify the traditional teaching models, teachers and learners could cooperate together to promote the ability of "learning to learn". In other words, technology comes to the human community is not to replace the old way of learning, but to enrich and complement what has been there.

Information has become central to every domain of human life and pervasive in every venue of human existence (Bosco, 1995). Meanwhile, the main goal of learning is to gain information and be able to use it. The skills of obtaining, integrating, and using information are everyone's needs which should be acquired in this $21^{\text {st }}$ century. Mastering these abilities helps learners to be successful in the competitive global job market and to fulfill roles as active citizens in a democratic society (Ornstein, Levine, and Gutek, 2011).

According to Graddol in Pun (2013), technology, lies at the heart of the globalization process and affecting education work and culture. Technology provides a wide selection so that they can customize the learning styles. For 
example, learners can learn with games they can enjoy. They can also be involved in learning and teaching based on interests. In addition, technology has been accepted in the world as a tool that facilitates humanity in all aspects of life. Meanwhile, technology complements the traditional teaching methods that have been applied to the classroom. Other than that, technology allows learners to connect to the target language culture. On the other hand, according to Lee et al. (2011: 15), foreign language learners studying in their home countries are often faced with the simple truth that once they leave the classroom there is no guarantee that they will be given opportunities to use the target language. Technologies provide opportunities to learn outside the classroom.

\section{PREVIOUS STUDIES}

Several studies have been conducted related to the use of technology in language learning. Tour conducted a study about digital mindsets of teachers' technology use in personal life and teaching. Three participants were involved in the qualitative research. All of them were teachers with more than five years experiences. Through interviews and participantgenerated photography (10-15 images of participants using technology in personal life), it shows that participants used technology in different ways. The purpose of technological usage was reinforcement and consolidation of language skills for students. Another goal in the utilization of technology was to find opportunities to expand the network of fellow educators. With technology, teachers could share knowledge, information, and tips not only with the teachers in the same region but also with teachers around the world. Exploring suitable activities which were workable for students was also the teachers' purpose in using technology.

Another study was conducted by Chryso (2016) who investigated learners' attitudes and motivation for learning Turkish, the second official language of the Republic of Cyprus, with the help of computer technology. There were 26 participants in the University of Cyprus which were involved in the mix-method research using questionnaires and interviews. The results show that students' motivation in learning Turkish with computer technology was for finding a good job and acquiring better knowledge about Turkish grammar and syntax. Most of them used the online game like Kahoot and opening Facebook. The listening materials which most of them used could be the digital tool Vacarro. For the Pbworks, this platform had an effective role in language learning. Meanwhile, the WiZiQ platform did not contribute a lot to learning Turkish.

Burgess et al. (2012) investigated a platform called multiuser virtual environments (MUVEs) that allowed students to engage in learning opportunities congruent with digital literacy. The data were collected through mix-methods from 80 college-level students enrolled in four sections of a developmental reading course and divided into a control group and an experimental group. The control group experienced face-to-face lecture and instruction, whereas the experimental group experienced both face-to-face lecture and supplemental instruction within the virtual environment. The results revealed that, although participants in this study were digitally literate, the experimental group achieved more reading scores than the control group. However, using virtual environment also required instructors to have digital literacy skills.

Sadaf and Johnson (2017) studied teachers' beliefs related to their intention of integrating digital literacy in the classroom. The theoretical framework used in this exploratory qualitative research was Ajzen's Theory of Planned Behavior which was consisted of behavioral beliefs (attitude toward outcomes of a behavior), normative beliefs (social support), and control beliefs (perceived behavioral control). The results for behavioral beliefs showed that digital literacy could develop students' $21^{\text {st }}$-century skills ( $\left.80 \%\right)$, improve students' engagement in the classroom (62\%), and prepare them 
for future careers (32\%). In normative beliefs, influences in integrating digital literacy were from their administrators' expectations (84\%), colleagues' (46\%), parents' (46\%), and students' expectation (40\%). In control beliefs, $78 \%$ of the teachers reported that access to technology was an important factor in integrating digital literacy, besides sufficient teacher training (36\%) and access to digital literacy curriculum resources (32\%).

\section{METHOD}

This study was a qualitative research to describe learners' experiences in integrating technology for their foreign language learning. However, the results of this study are not intended to reflect the whole implementation of technology in foreign language learning. It considers that different places, regions, or circumstances can affect the results.

\section{Participants}

Three participants were involved in this research as informants, namely Dinda, Heny, and Ami. They are all women whom the researcher meets in the academic field. Dinda (25) is a friend since Junior High School. In the past thirteen years, Dinda joins the same Islamic community as the researcher. From 2010 to 2015, the researcher lived in the same house in Yogyakarta with her while pursuing the undergraduate degree. Until this research was conducted, Dinda studied five languages in formal (English, Arabic, and French) and informal (Japanese and Korean). Another participant is Heny (25), who studies, English as a foreign language for years and meets the researcher in a postgraduate study. She learned French for a while by autodidact learning and Korean informally. The last participant is Ami (31) whom the researcher also meets at a postgraduate study. She learns English in formal education for years, Korean (formal and informal), and two other languages (Spanish and Esperanto) by autodidact learning. The reason why the researcher asked these women to participate in this study is that they learn various languages which are not commonly studied in Indonesia as foreign languages.

\section{Instruments}

The data were collected by using an interview guideline and informal observation. The informal observation was conducted at the same time as the interview took place by asking the participants to demonstrate the digital technology they usually used.

\section{Procedure}

The steps to collect the data were explained below

- The researcher determined the research participants.

- The interview guideline was formulated to find the intended information.

- The interview was held.

- The data were collected and analyzed.

\section{Data Analysis}

The data obtained in this study would be analyzed qualitatively based on the three main components of qualitative data analysis proposed by Miles and Huberman in Hamied (2017: 217). The three procedures are data reduction, data display, and drawing and verifying conclusion. In data reduction, the researcher edited, segmented, and summarized to 
look for the intended information. Themes, clusters, and patterns were concerned without reducing the significant loss of information. In data display, the researcher, organized and compared the information with the other sources. In drawing and verifying conclusion, the researcher verified the gathered data and made the conclusion about the information.

\section{ANALYSIS}

From the interviews, the collected data were analyzed and categorized as themes below. It covers technology integration in autodidact learning and formal education, technology and learning tools, languages specific challenges, and technology and skills developments.

\section{Technology Integration in Autodidact Learning and Formal Education}

From interviews with three participants, each of them had experienced both formal education and self-taught learning. When studying formally, technology is widely used by teachers to facilitate the delivery of materials. They usually use videos, power points, and textbooks that can be obtained in $p d f$ format. Teachers provide teaching materials, links to videos or websites, and so on based on learners' levels, whether they are a beginner, intermediate, or advanced. Formal education provides books, practices, and so on in a systematic learning. This learning occurs systematically and structurally following the designed curriculum.

Meanwhile, not all language learners tend to choose the formal education in language learning. Dinda said that she did not really enjoy formal education. She prefers autodidact learning to understand her target language.

"I don't like learning which is too systematic according to the curriculum." (Dinda)

For autodidact learning, she learns most from the internet and asking friends who studied the same target language as her. Technology gives benefits in sharing files with her friends and to communicate. In this case, technology gives big roles in her autodidact learning style. The same opinion also goes for Ami. According to her, technology helps a lot for autodidact learning.

"Technology helps a lot in my language learning, especially for autodidact learning." (Ami)

"For my Korean class, it usually relies on books. Before I take a Korean course, I learned more through websites." (Ami)

Ami experienced a Korean course and autodidact learning. According to her, Korean language courses often rely on books designed based on the learners' stages. However, before she attended the course, she learned Korean in autodidact learning by using learning websites.

The advantage of autodidact learning is that learners can choose their teaching materials based on learners' interest. With the technology access, they are able to get a variety of sources. Whatever they want can be provided by digital technology. From the analysis based on their experiences, technology roles are more pronounced for autodidact learning than for formal education.

\section{Technology and Learning Tools}

The participants use different kinds of tools as their favorite. For Dinda, she often uses learning materials in the form of video and audio. Sometimes, she opens an internet browser to search for articles or teaching materials to learn the basic structure of a sentence. She also uses existing apps that have been installed on her phone or laptop. The digital 
dictionary is always a choice which should be installed in the gadget that she has.

"I often use the internet for learning.... Most of them are videos, for example, YouTube. Texts are not really interesting for me." (Dinda)

"I learn Japanese through videos such as movies, dramas, or a cut of news or variety shows. I heard and watched it with subtitles. From those videos and subtitle, I know the meaning of what they say. Because I do it regularly, I can filter the sentences and I know the structures of their sentences." (Dinda)

When Dinda found a sentence structure she did not know, searching articles is the option. Sometimes, she asked friends about the sentences by using chat application on her phone.

"Actually, video, audio, and texts complete one another. When I found something in videos, for example, a word, and... also... written and spoken languages are different, so, I search articles or asking friends about that word or sentences." (Dinda)

Heny also used videos such as news, documentary video, or movies. She also used a digital dictionary. Since French has different vocabularies which is dealing with grammatical gender, the digital dictionary helps her in differentiating words for masculine and words for feminine. It is easy to be used and installed in her computer. More importantly, it is free.

"I had an application named conju-conjugation... conjuga... I forgot the application name, but it is a kind of converter. In French, there are so many verbs and it is difficult to memorize. The dictionary helps me to differentiate the verbs." (Heny)

For Ami’s experiences, she often used language learning application named Duolingo. It provides a wide variety of languages around the world and includes training to improve the four language skills. There is also a learning site called Talk to Me in Korean. It has websites, fan pages, and social media accounts that serve to share teaching materials.

"Duolingo is an application in the play store. A lot of language choices, ranging from popular language to languages such as Esperanto, Romanian, and others. That's a lot of it. We can choose courses and can take any class according to desire and passion. Then there will be the material. Actually, the material is not too much. But Duolingo is good for review. For beginners, that's good." (Ami)

"Talk to Me in Korean is good. They have a very good curriculum, from level 1 to level 9. There are videos, there are podcasts too, voices recordings, materials, exercises, and everything is complete there. Many learning materials are provided there in the form of e-books, audio.... Then, the exercises are also provided. That's quite interactive, great." (Ami)

Other than Talk to Me in Korean, according to Ami, there is Sejonghakdang site. Learners take exercises directly on the websites. There are materials which explain grammar and so on, give examples, and provide exercises. Learners can immediately know the score and how many questions they could answer correctly. Later, Ami joined a community for multilingual language speakers that she found out through Instagram.

The above explanation could be summarized in Table 1 below. 
Table 1: Learning Tools which are Frequently used

\begin{tabular}{|l|l|}
\hline Name & \multicolumn{1}{|c|}{ Learning Tools which are Usually Used } \\
\hline Dinda & $\begin{array}{l}\text { Using video, audio, and scanned magazines frequently for extensive } \\
\text { learning }\end{array}$ \\
\hline Heny & $\begin{array}{l}\text { Using video (mostly from YouTube) and digital dictionary in her } \\
\text { leisure activities, and writing in blogs }\end{array}$ \\
\hline Ami & $\begin{array}{l}\text { Using language learning applications (Duolingo), websites (Talk to } \\
\text { Me in Korean and Sejonghakdang), and joining language } \\
\text { communities (Polyglot) which could be found from social media and } \\
\text { internet }\end{array}$ \\
\hline
\end{tabular}

From the table, the three participants applied learning tools in different ways. For Dinda, learning tools she used to often deal with video and audio. She downloads materials from campus or places that provided wi-fi and bring it home. She opened video players and enjoyed language learning in extensive ways. When she found something interesting from the video, she searched it on the internet, opened the digital dictionary, or asked her friends who studied the same target language. Then, she continues watching the video. Since she likes Japanese artist, she tried to download digital magazines which are written in hiragana or katakana, kinds of Japanese writing symbols. Dinda trained her reading skills from there.

In Heny's experiences, videos are interesting materials for her learning. She usually watches video from YouTube. The application she usually uses is a digital dictionary which is integrated into her laptop. While watching the video on her laptop, she could open it to check the words. Another digital learning tool is a blog. Her writing skills improve a lot because of the blog she maintained.

For Ami's experiences, she uses technology not only to learn, but also to find communities and broadens friendships with fellow language learners. She often uses learning applications, such as Duolingo, and attends multilingual speaker meetings that she finds the information through social media.

According to Ami's point of view, do not let the teachers just come to the class, play videos, give the tasks to the learners. Later, they do not have to correct students work because some applications or websites properly show learners' scores from doing the tasks automatically. Although the technology is really helpful for language learners, do not let the use of technology makes teachers lazy to teach.

\section{Language Specific Challenges}

The interview finds several languages that have specific challenges in learning. Languages that have different writing symbols than the mother tongue certainly have different challenges. Some digital technology provides applications for learners who had different written symbols with their mother tongue. As the example, learning Japanese and Korean has different writing symbols. Japanese writings consist of hiragana, katakana, and kanji while Korean has hangul.

“Japanese doesn't have the same written symbol as English which uses alphabets as Bahasa Indonesia. They use kanji, hiragana... Because I cannot read those symbols, I search websites which use romaji. That's why, when it comes to writing, I can do nothing.” (Dinda)

"I know how to write Japanese from my friend. In writing Japanese, there is a term called stroke or scratches. Each word contains different numbers of scratches and it is categorized in the digital dictionary based on those numbers of stroke." (Dinda) 
When Dinda found a word written in Japanese symbol, she counted the number of a stroke of the word and searched it in a digital dictionary. She preferred romaji than Japanese symbols in collecting learning materials. Romaji is Latin scripts to write or read the Japanese language. For an example, the word “わたし“ is written in hiragana. In romaji, it is written as "watashi" which means "I". Other than that, according to Dinda, Japan is a very strict state of copyright protection. It is not easy to find free Japanese language materials uploaded. Sometimes, Dinda has to search the websites to simply find the opening key of the download site.

Ami has Korean writing books where she can practice her writing skills. She joins a Korean class for several months. Attending a Korean course requires her to complete stages of learning to improve her skills. At the early stage, she learns Korean symbols for reading and writing in the class.

Technology does give a lot of conveniences. However, for certain languages that have the symbol of writing different from the first language, it would be good if there is guidance from someone who better understands. With the direction of people who are more familiar with the target language, the use of technology can be applied maximal for teaching tools.

\section{Technology and Skills Developments}

Four language skills can be sharpened using technology, which could be found in learners' everyday activities. For reading skills, technology helps them to search readable learning materials from various sources not only for selftaught learning but also for formal education.

From Dinda's experiences, she looked for a scan of Japanese magazines and try to read and understand the information. However, she chose the letter written in romaji because it is easier than all Japanese alphabets. In Japanese letters, there are procedures for writing that the scratches should not be written randomly. There are stages of the line that must be done to form a letter. Although technology provides applications that help in writing, it is not maximally used by Dinda. The writing applications provided was not maximally used.

"Since I learn more from video and audio, I start to feel difficult when it comes to writing activities. Writing is so difficult for me." (Dinda)

On the other hand, improving writing skills was not a problem for Ami. According to her, technology covers writing practices in her learning. Sometimes, she wrote captions in social networks using her target language. Before uploading content on social networks, she had to check the spelling and grammar.

Meanwhile, the skill which was improved the most for Dinda is listening. She likes hearing video and audio because of the accents. From the video, she learns how to pronounce the words. Although she learns how to pronounce, it does not mean that speaking is simple for her. When it comes to communicating, there should be interactions between two or more people, which she did not get it by digital technology she used. In reality, native speakers of Japanese are not like in the videos which were well-organized and scripted.

Ami also agrees that speaking is the skill which has the slowest development when it comes to the use of technology.

"Speaking skill is not well-covered." (Ami) 
"For reading, listening, and writing, it is enough to use Sejonghakdang and Duolingo because the applications cover the skills improvement. However, the weaknesses... not facilitating, not yet facilitating, for speaking skills. Although Duolingo has speaking practices, it is different with real communication where I talk, you answer.” (Ami)

Features for learning speaking have not been widely developed in digital technology. According to Ami, although there are applications that help her check the pronunciation, for example in Duolingo, that is not enough to improve speaking skills. According to her, speaking is when someone is able to convey information orally, not only just mastering the pronunciation but also knowing how to communicate. Communication skills in speaking could be obtained if learners have a partner involved in speaking activities because there are people who can talk to. The two-way communication is what Ami thinks will help learners to get speaking skills.

\section{DISCUSSIONS}

Technology is integrated into every learning, not just language learning. Although the technology provides a lot of convenience in learning practice, learners should have skills in filtering the input. With these skills, the processing information they got is expected to be maximally done.

When learning a language that has symbols of writing different from the first language, it is recommended to learn the symbols first. Punctuation and directionality also should be introduced first (Saville-Troike, 2006). Directionality deals with the direction where the first letter starts, for an example, Arabic is written from right to left. The Japanese could be written from top to bottom. In punctuation, some language, letters do not need spaces between words, for an example, Chinese. In Dinda's case, she trained her listening first and found it difficult when faced Japanese writing. Instead of learning Japanese writing symbols which are katakana, hiragana, or kanji, she chose romaji. On the other hand, Ami not only intensely trains her listening skills, but rather sharpens her writing skills as well. With the lessons she learned in a Korean language course, she began to be introduced to the hangul letters. This is what distinguishes the process of selftaught and formal learning.

Based on the interviews, three participants involved their auditory to catch the sounds of languages they learn. According to Saville-Troike (2006), listening to a foreign language is perceived as a stream of noise. The first step to do is to recognize the patterns in recurring sequences of sounds to catch the meaning. By recognizing the patterns, learners could catch the meaning, although it is done by top-down processes.

Meanwhile, it seems that the longer a person studies the target language, the more sources known to learn the language. Even though one learns a language longer, it does not guarantee that the person takes advantage of technology more maximally than the new learner.

\section{CONCLUSIONS}

Technology roles are more pronounced for autodidact learning than for formal education. Each learner has different favorite tools which they usually use. However, videos and digital dictionaries are commonly used as learning tools between learners. Although there are many languages learning applications developed, speaking skill is hard to be covered. For certain languages that have different writing symbols from learners' first language, the use of technology could not be applied maximal. In other words, the impact of technology is more pronounced to the development of receptive skills. 
Meanwhile, technology does not only improve language skills, but also to expand the networks to meet communities of language learners. It provides many options in language learning. In this $21^{\text {st }}$ century, learners have more access to gain information they want to improve language skills. With technology, learners have opportunities to choose their learning styles, strategies, materials, what languages they want to learn, and even choosing communities. Instead of replacing the old way of learning, technology comes to human communities as complements which enrich what has been there.

\section{REFERENCES}

1. Bosco, J. (1995). Schooling and learning in an information society. In Office of Technology Assessment, Future visions: Education and technology (pp. 25-56). Washington, DC: U. S. Government Printing Office.

2. Burgess, M. L., Price, D. P., and Caverly, D. C. (2012). Digital Literacies in Multiuser Virtual Environments among CollegeLevel Developmental Readers. Journal of College Reading and Learning, 43(1), 13-30.

3. Chryso, P. (2016). Students' attitudes and motivation towards technology in a Turkish language classroom. In S. PapadimaSophocleous, L. Bradley \& S. Thouësny (Eds), CALL communities and culture - short papers from EUROCALL 2016. 113118.

4. Hamied, Fuad Abdul. (2017). Research Methods: A Guide for First-Time Researchers. Bandung: UPI Press

5. Lee, Richard A., Browne, Kevin C., \& Kusumoto, Yoko. (2011). Measuring EFL Learners' Environment: English Contact and Use outside the Classroom at a Japanese International University. Polyglossia, 20(_), 15-25.

6. Lintunen, P., Mutta, M., and Pelttari, S. (2017). Profiling Language Learners in Hybrid Learning Contexts: Learners' Perceptions. The EUROCALL Review, 25(1), 61-75).

7. Ornstein, A. C., Levine, D. U., \& Gutek, G. L. 2011. Foundation of Educations. 11 $1^{\text {th }}$ Edition. Belmont: Wadsworth

8. Pun, Min. (2013). The Use of Multimedia Technology in English Language Teaching: A Global Perspective. Crossing the Border: International Journal of Interdisciplinary Studies, 1(1), 29-38.

9. Sadaf, Ayesha \& Johnson, Barbara L. (2017). Teachers' Beliefs about Integrating Digital Literacy into Classroom Practice: An Investigation Based on the Theory of Planned Behavior.

10. Rahi, Avtar Singh. "Technology, Scientific Attitude and Human Behaviour: A Review."

11. Saville-Troike, M. (2006). Introducing second language acquisition. Cambridge: CUP

12. Schleicher, Andreas. (2012). Preparing Teachers and Developing School Leaders for the 21st Century: Lessons from around the World. OECD Publishing

13. Sharma, P. and Barrett, B. (2007). Blended Learning: Using Technology in and beyond the Language Classroom. Oxford: Macmillan Publishers Ltd

14. Tour, Ekaterina. (2015). Digital Mindsets: Teachers' Technology Use in Personal Life and Teaching. Language Learning and Technology, 19(3), 124-139.

15. Villafuerte, J. and Romero, A. (2017). Learners' Attitudes toward Foreign Language Practice on Social Network Sites. Journal of Education and Learning; 6(4), 145-158. 